\section{Distributed versus massed training: efficiency of training psychomotor skills}

\author{
Koen W. van Dongen, ${ }^{1,2}$ Peter J. Mitra, ${ }^{2}$ \\ Marlies P. Schijven, ${ }^{3}$ Ivo A.M.J. Broeders ${ }^{4}$ \\ 'Department of Surgery, Twee Steden \\ Hospital, Tilburg; ' ${ }^{2}$ epartment of \\ Surgery, University Medical Centre, \\ Utrecht; ${ }^{3}$ Department of Surgery, \\ Academic Medical Centre, Amsterdam; \\ ${ }^{4}$ Twente University, Institute of Technical \\ Medicine/Department of Surgery, \\ Meander Medical Centre, Amersfoort, \\ The Netherlands
}

\section{Abstract}

Virtual reality simulators have shown to be valid and useful tools for training psychomotor skills for endoscopic surgery. Discussion arises how to integrate these simulators into the surgical training curriculum. Distributed training is referred to as short training periods, with rest periods in between. Massed training is training in continuous and longer training blocks. This study investigates the difference between distributed and massed training on the initial development and retention of psychomotor skills on a virtual reality simulator. Four groups of eight medical students lacking any experience in endoscopic training were created. Two groups trained in a distributed fashion, one group trained in a massed fashion and the last group not at all (control group). All performed a post-test immediately after finishing their training schedule. Two months after this test a second post- test was performed. The one-way analysis of variance (ANOVA) with Post-Hoc test Tukey-Bonferoni was used to determine differences in mean scores between the four groups, whereas a pvalue $\leq 0.05$ was considered to be statistically significant. Distributed training resulted in higher scores and a better retention of relevant psychomotor skills. Distributed as well as massed training resulted in better scores and retention of skills than no training at all.

Our study clearly shows that distributed training yields better results in psychomotor endoscopic skills. Therefore, in order to train as efficient as possible, training programs should be (re)-programmed accordingly.

\section{Introduction}

The introduction of endoscopic surgery has introduced new challenges in surgical educa- tion. A difference in skills is required for endoscopic surgery compared to traditional open surgery, because of the different operating setting. Endoscopic surgery requires 3-D orientation in a 2-D representation of the operating scene, as well as endoscopic instrument handling. ${ }^{1-4}$ Virtual reality simulators have shown to be valid and useful tools for training these psychomotor skills. ${ }^{5-9}$ Working hours of residents have been limited during the last years and technical skill training should be as efficient as possible. Therefore it is very important to understand the concepts of training schedules. Essentially one can choose between a distributed and a massed set-up.

Distributed training is referred to as short training periods, with rest periods in between. ${ }^{10,11}$ Massed training is described as training in continuous and longer training blocks. ${ }^{10,11}$ In studies on sports and psychology there is a difference in favour of the distributed training, both for initial results as well as for retention of knowledge and skills.

Only a few studies have investigated the influence of training schedules on the attainment of surgical technical skills..$^{9,12}$ These studies also show superiority for distributed training. The purpose of this study therefore was to investigate the effect of distributed and massed training on the initial development and retention of psychomotor skills on a virtual reality simulator.

\section{Materials and Methods}

\section{Sample size}

A power analysis based on the results of time-scores analysis (relative difference $18.7 \%$ ) in the study of Verdaasdonk et al..$^{9}$ with a power of 0.8 and alpha set at 0.05 , demonstrate a group size of 8 participants for each group.

\section{Participants}

A total of 32 Medical students (undergraduate in the final year of study) without any prior experience in endoscopic basic skills training were recruited from the Faculty of Medicine of the Utrecht University and randomly assigned into four groups of eight subjects each (Table 1).

\section{Apparatus, tasks and training}

The simulator used was the LapSim virtual reality surgical simulator, featuring LapSim Basic Skills 2.5 software (Surgical Science Ltd, Göteburg, Sweden). The following seven tasks at easy, medium and hard level were selected and object of research; camera navigation, instrument navigation, coordination, grasping, lifting and grasping, cutting and clipping and cutting13. All participants performed the same
Correspondence: Koen W. van Dongen, Department of Surgery, University Medical Centre, Heidelberglaan 100, 3584 CX, Utrecht, The Netherlands. E-mail: kvdongen@tsz.nl

Key words: surgical training, laparoscopic surgery, virtual reality.

Received for publication: 4 July 2011. Accepted for publication: 28 August 2011.

This work is licensed under a Creative Commons Attribution NonCommercial 3.0 License (CC BYNC 3.0).

(C) Copyright K.W. van Dongen et al., 2011

Licensee PAGEPress, Italy

Surgical Techniques Development 2011; 1:e17

doi:10.4081/std.2011.e17

training program. In every session all seven tasks were performed at three different levels (easy, moderate, hard). Scores were derived from the 178 measured parameters which were categorized, based on the quartile scores of 48 subjects in a prior study13. Scores are represented in percentages $(0-100 \%)$ relative to a pre-set benchmark score, derived from expert performances. An 80 percent score on an exercise equals 80 points. All exercises were explained to the participants and they were allowed to try all exercises once at easy level to get acquainted with the simulator. All participants then performed a pre-test.

\section{Training schedules}

Group one trained on two separate days within one week. Each day they trained four consecutive hours (massed training). Group 2 trained on eight separate days within two consecutive weeks, (distributed). Each day they trained one hour. Group three trained on eight separate days within four consecutive weeks (wide distributed). Each day they trained one hour. Group four is a control group, which did not train at all.

All performed a post-test immediately after finishing their training schedule (post-test 1). Two months after post test 1 a second post- test was performed (post-test 2). Group four performed their post-test 1 one month after the pre-test (according to the longest training schedule) (Figure 1).

\section{Evaluation}

All training tasks were evaluated at the hard level. Data analysis was done using SPSS, version 15.0. The one-way analysis of variance (ANOVA) with Post-Hoc test Tukey-Bonferoni was used to determine differences in mean scores between the four groups, whereas a $\mathrm{P} \leq 0.05$ was considered to be statistically significant. 


\section{Results}

Table 1 shows the characteristics of the groups. There is a normal distribution of the characteristics and data concerning other possible contributors to improving basic psychomotor skills.

\section{Pre-test}

Table 2 shows the scores of the four groups during the pre-test which do not differ significantly different $(\mathrm{P}=0.841)$. All groups achieved a comparable score between 405 and 444 points.

\section{Post-test 1}

The scores of the post test 1 differ significantly $(\mathrm{P}=0,000)$. Figure 2 shows the results of the scores on post test 1 and 2 . Group 1 trained in a massed model and scored 686 points, which is significantly lower than the two groups trained by a distributed trainings scenario (group 2 (809 points, $\mathrm{P}=0.032$ ) and Group 3 (795 points, $\mathrm{P}=0.036$ ); respectively). All groups score significantly higher than group 4 (474 points, $\mathrm{P}=0.001$ ).

The scores of group 2 and 3 are equivalent $(\mathrm{P}=0.494)$. Both group 2 and 3 score significantly higher than the non-trained group 4 ( $\mathrm{P}=0.001, \mathrm{P}=0.01$ respectively).

\section{Post-test 2}

Table 2 and Figure 2 show that the scores of the groups at post test 2 are significantly different. Two months after their last training group 1 performs worse than immediately after training (546 versus 668). Their scores are lower than those of group $2(679, \mathrm{P}=0.036)$ and $3(678, \mathrm{P}=0.027)$. The scores of group 1 are significantly higher than those of group 4 (357, $\mathrm{P}=0.007)$. Group 2 and 3 achieve similar scores ( 679 and $678, \mathrm{P}=0.753$ ), which are lower than their initial scores immediately after their training program (809 and 795). These scores are also significantly higher than the scores of group 4 ( $\mathrm{P}=0.002$ and $\mathrm{P}=0.001$ respectively).

Table 1. Demographic group characteristics.

\begin{tabular}{|c|c|c|c|c|}
\hline Groups & 1 & 2 & 3 & 4 \\
\hline $\mathrm{N}$ & 8 & 8 & 8 & 8 \\
\hline \multicolumn{5}{|c|}{$\begin{array}{l}\text { Characteristics } 24 \text { (21-28) } 24.4 \text { (21-30) } 23.9 \text { (19-29) } 24 \text { (19-33) } \\
\text { mean age (range) }\end{array}$} \\
\hline Male:female & $4: 4$ & $5: 3$ & $5: 3$ & $3: 5$ \\
\hline $\begin{array}{l}\text { Right hand } \\
\text { dominance (N) }\end{array}$ & 7 & 8 & 7 & 7 \\
\hline $\begin{array}{l}\text { Medical } \\
\text { background }(\mathrm{N})\end{array}$ & 8 & 8 & 8 & 8 \\
\hline $\begin{array}{l}\text { Computer game } \\
\text { experience }(\mathrm{N})\end{array}$ & 3 & 3 & 3 & 2 \\
\hline $\begin{array}{l}\text { Playing an } \\
\text { instrument }(\mathrm{N})\end{array}$ & 6 & 5 & 6 & 5 \\
\hline
\end{tabular}

\section{Discussion}

In our study, distributed training result in higher initial scores and a better retention of psychomotor skills needed for endoscopic surgery on a virtual reality simulator. These results substantiate the findings of earlier studies on technical surgical and psychomotor skills. ${ }^{9,12}$

Superiority of distributed training above massed training schedules is known from studies in sports and psychology. Dail et al. examined judgments of learning and the longterm retention of a discrete motor task (golf putting) as a function of distributed practice..$^{10}$ The results indicated that participants in the distributed practice group performed more proficiently than those in the massed practice group; during both acquisition and retention phases. Lee et al. have shown that massed training is superior only in single task training. ${ }^{11}$ In their study, a movement timing task was performed. When training a continuous task, (multiple timing moments in one task) instead of a single task (one timing moment only), distributed training is superior. Training psychomotor basic skills must be considered as a form of continuous training. Therefore our results are in line with the results of Lee et al.,
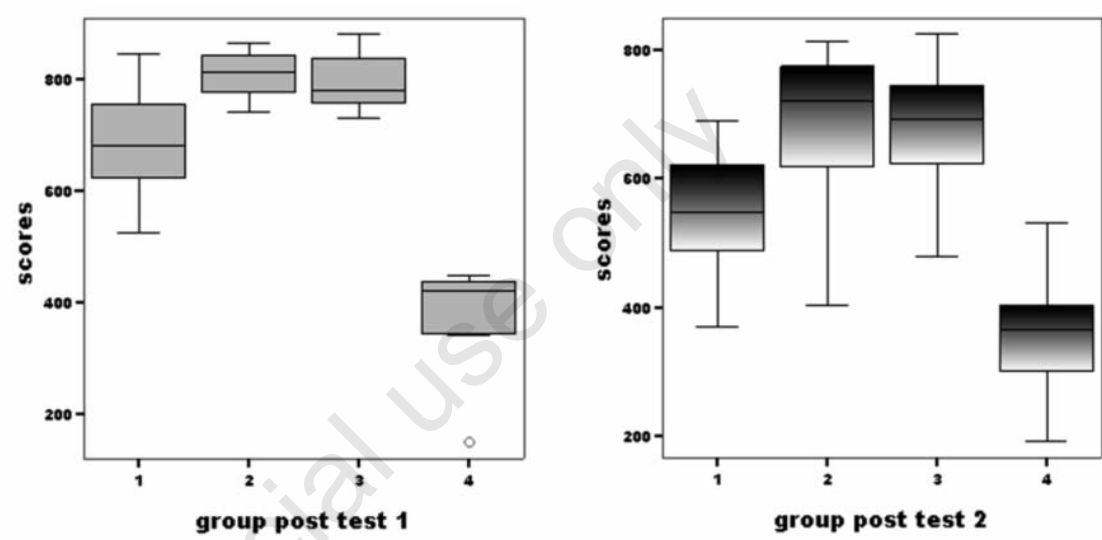

Figure 1. Training schedules.
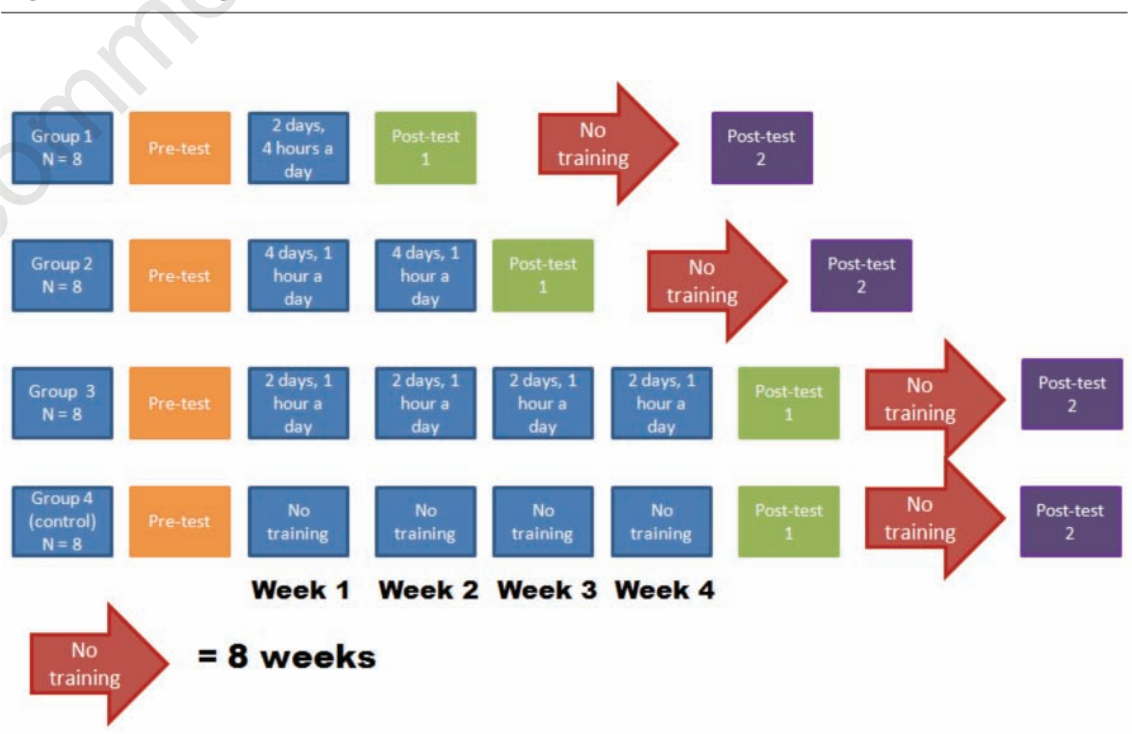

Figure 2. Scores per group at post-test 1 and post-test 2 .

Table 2. Mean total scores (range) per test, per group.

\begin{tabular}{lcccc} 
& Group 1 & Group 2 & Group 3 & Group 4 \\
Pre-test & $434(259-529)$ & $444(312-503)$ & $422(341-521)$ & $405(298-516)$ \\
Post-test 1 & $686(525-847)$ & $809(742-866)$ & $795(730-881)$ & $374(341-449)$ \\
\hline Post-test 2 & $546(369-750)$ & $679(402-814)$ & $678(479-824)$ & $357(257-530)$ \\
\hline
\end{tabular}

[Surgical Techniques Development 2011; 1:e17]

[page 41] 
favouring distributed training above massed training.

All studies show that distributed skills training is to be preferred, although a solid scientific explanation for this is unknown so far. An explanation might be that caused by the development of new or more efficient neuro-networks in the brain during the rest periods, thus enhancing consolidation of newly acquired skills. Walker et al have shown that changes in the brain do take place during rest period. ${ }^{14}$ All 12 subjects were trained in a finger tapping task and $12 \mathrm{~h}$ later were retested during functional magnetic resonance imaging. When a period of sleep was in between the MRI showed regions of increased activation. In contrast, if there was no sleep in the $12 \mathrm{~h}$ period signal decreases were identified.

Retention of psychomotor skills is reinforced by resting periods, possibly because the brain needs these periods to store the learned skills and to avoid negative effects of tiredness. ${ }^{9}$ The distributed training schedules of group 2 and group 3 did not show any difference. Authors could not establish arguments for benefits of a schedule of two weeks, almost every day once, or within four weeks with a rest period of two to three days. One might say that as long as there is a resting period, training is more likely to become part of one's palette of internalized skills. The sleep dependency of training motor skills as described above could explain this.

The groups that trained by a distributed schedule, (Group 2 and 3), scored better both directly after the training as well as two months later. These differences are indicative for superiority of distributed training program regarding retention of skills $(\mathrm{P}=0.0 .027$ and $\mathrm{P}=0.007)$. Moulton et al.12 have shown a significant difference in complex technical surgical skill (performing a microvascular anastomosis) after one month without skills training. Apparently, when training complex tasks, distributed training is even more distinctive to attain retention of skills compared to training basic psychomotor skills. In a study on training psychomotor skills on a virtual reality simulator by Verdaasdonk et al., ${ }^{9}$ participants' scores did also significantly differ in favour of the distributed trained group. In this study, retention was scored after a period of one week. Although a decrease in performance was seen in both groups, the difference remained significant after a week.

Throughout literature, a decrease in scores is seen after periods without training. Therefore, authors suggest that pre-clinical skills training should immediately be followed by training in the operating theatre.

\section{Conclusions}

Distributed training is superior to massed training in acquiring and retaining psychomotor skills for endoscopic surgery on a virtual reality simulator.

The current training programs in the Netherlands are usually based on a two or three day regime, which provides a possibility for massed training only. In contrast, the results of our study show that distributed training should be advised in training psychomotor endoscopic skills. Therefore, in order to train as efficiently as possible, training programs should be rescheduled thus redesigned accordingly. Furthermore, residents should be facilitated to execute their newly learned skills preferably in the operating theatre immediately after training.

\section{References}

1. Gallagher AG, McClure N, McGuigan J, et al. An ergonomic analysis of the fulcrum effect in the acquisition of endoscopic skills. Endoscopy 1998;30:617-20.

2. Hanna GB, Shimi SM, Cuschieri A. Randomised study of influence of twodimensional versus three-dimensional imaging on performance of laparoscopic cholecystectomy. Lancet 1998;351:248-51.

3. Hanna GB, Cuschieri A. Influence of the optical axis-to-target view angle on endoscopic task performance. Surg Endosc 1999;13:371-5.
4. Moore MJ, Bennett CL. The learning curve for laparoscopic cholecystectomy. The Southern Surgeons Club. Am J Surg 1995;170:55-9.

5. Aggarwal R, Ward J, Balasundaram I, et al. Proving the effectiveness of virtual reality simulation for training in laparoscopic surgery. Ann Surg 2007;246:771-9.

6. Ahlberg G, Heikkinen T, Iselius L, et al.Does training in a virtual reality simulator improve surgical performance? Surg Endosc 2002;16:126-9.

7. Grantcharov TP, Kristiansen VB, Bendix J, et al. Randomized clinical trial of virtual reality simulation for laparoscopic skills training. Br J Surg 2004;91:146-50.

8. Gurusamy K, Aggarwal R, Palanivelu L, Davidson BR. Systematic review of randomized controlled trials on the effectiveness of virtual reality training for laparoscopic surgery. Br J Surg 2008;95:1088-97.

9. Verdaasdonk EG, Stassen LP, van Wijk RP, Dankelman J. The influence of different training schedules on the learning of psychomotor skills for endoscopic surgery. Surg Endosc 2007; 21:214-9.

10. Dail TK, Christina RW. Distribution of practice and metacognition in learning and long-term retention of a discrete motor task. Res Q Exerc Sport 2004;75:14855.

11. Lee TD, Genovese ED. Distribution of practice in motor skill acquisition: different effects for discrete and continuous tasks. Res Q Exerc Sport 1989;60:59-65.

12. Moulton CA, Dubrowski A, Macrae H, et al. Teaching surgical skills: what kind of practice makes perfect?: a randomized, controlled trial. Ann Surg 2006; 244:400-9.

13. van Dongen KW, Tournoij E, van der Zee DC, et al. Construct validity of the LapSim: Can the LapSim virtual reality simulator distinguish between novices and experts? Surg Endosc 2007;21.1413-7.

14. Walker MP, Stickgold R, Alsop D, et al. Sleep-dependent motor memory plasticity in the human brain. Neuroscience 2005; 133:911-7. 